\title{
Complicated intra-abdominal infections worldwide: the definitive data of the CIAOW Study
}

Massimo Sartelli $i^{*}$, Fausto Catena ${ }^{2}$, Luca Ansaloni ${ }^{3}$, Federico Coccolini ${ }^{3}$, Davide Corbella ${ }^{4}$, Ernest E Moore ${ }^{5}$, Mark Malangoni ${ }^{6}$, George Velmahos ${ }^{7}$, Raul Coimbra ${ }^{8}$, Kaoru Koike ${ }^{9}$, Ari Leppaniemi ${ }^{10}$, Walter Biffl ${ }^{5}$, Zsolt Balogh $^{11}$, Cino Bendinelli ${ }^{11}$, Sanjay Gupta ${ }^{12}$, Yoram Kluger ${ }^{13}$, Ferdinando Agresta ${ }^{14}$, Salomone Di Saverio ${ }^{15}$, Gregorio Tugnoli ${ }^{15}$, Elio Jovine ${ }^{16}$, Carlos A Ordonez ${ }^{17}$, James F Whelan ${ }^{18}$, Gustavo P Fraga ${ }^{19}$, Carlos Augusto Gomes ${ }^{20}$, Gerson Alves Pereira Junior ${ }^{21}$, Kuo-Ching Yuan ${ }^{22}$, Miklosh Bala ${ }^{23}$, Miroslav P Peev ${ }^{7}$, Offir Ben-Ishay ${ }^{13}$, Yunfeng Cui ${ }^{24}$, Sanjay Marwah ${ }^{25}$, Sanoop Zachariah ${ }^{26}$, Imtiaz Wani ${ }^{27}$, Muthukumaran Rangarajan ${ }^{28}$, Boris Sakakushev ${ }^{29}$, Victor Kong ${ }^{30}$, Adamu Ahmed ${ }^{31}$, Ashraf Abbas ${ }^{32}$, Ricardo Alessandro Teixeira Gonsaga ${ }^{33}$, Gianluca Guercioni ${ }^{34}$, Nereo Vettoretto ${ }^{35}$, Elia Poiasina ${ }^{3}$, Rafael Díaz-Nieto ${ }^{36}$, Damien Massalou ${ }^{37}$, Matej Skrovina ${ }^{38}$, Ihor Gerych ${ }^{39}$, Goran Augustin ${ }^{40}$, Jakub Kenig ${ }^{41}$, Vladimir Khokha ${ }^{42}$, Cristian Tranà ${ }^{43}$, Kenneth Yuh Yen Kok ${ }^{44}$, Alain Chichom Mefire ${ }^{45}$, Jae Gil Lee ${ }^{46}$, Suk-Kyung Hong ${ }^{47}$, Helmut Alfredo Segovia Lohse ${ }^{48}$, Wagih Ghnnam ${ }^{32}$, Alfredo Verni ${ }^{49}$, Varut Lohsiriwat ${ }^{50}$, Boonying Siribumrungwong ${ }^{51}$, Tamer El Zalabany ${ }^{52}$, Alberto Tavares ${ }^{53}$, Gianluca Baiocchi ${ }^{54}$, Koray Das ${ }^{55}$, Julien Jarry ${ }^{56}$, Maurice Zida ${ }^{57}$, Norio Sato ${ }^{9}$, Kiyoshi Murata ${ }^{58}$, Tomohisa Shoko ${ }^{59}$, Takayuki Irahara ${ }^{60}$, Ahmed O Hamedelneel ${ }^{61}$, Noel Naidoo ${ }^{62}$, Abdul Rashid Kayode Adesunkanmi ${ }^{63}$, Yoshiro Kobe ${ }^{64}$, Wataru Ishii ${ }^{64,65}$, Kazuyuki Oka ${ }^{66}$, Yoshimitsu lzawa ${ }^{67}$, Hytham Hamid ${ }^{68}$, Iqbal Khan ${ }^{68}$, AK Attri ${ }^{13}$, Rajeev Sharma ${ }^{13}$, Juan Sanjuan ${ }^{17}$, Marisol Badiel ${ }^{17}$ and Rita Barnabé ${ }^{16}$

\footnotetext{
Abstract

The CIAOW study (Complicated intra-abdominal infections worldwide observational study) is a multicenter observational study underwent in 68 medical institutions worldwide during a six-month study period (October 2012-March 2013). The study included patients older than 18 years undergoing surgery or interventional drainage to address complicated intra-abdominal infections (IAls).

1898 patients with a mean age of 51.6 years (range 18-99) were enrolled in the study. 777 patients (41\%) were women and 1,121 (59\%) were men. Among these patients, 1,645 (86.7\%) were affected by community-acquired IAls while the remaining 253 (13.3\%) suffered from healthcare-associated infections. Intraperitoneal specimens were collected from $1,190(62.7 \%)$ of the enrolled patients.

827 patients (43.6\%) were affected by generalized peritonitis while 1071 (56.4\%) suffered from localized peritonitis or abscesses.

The overall mortality rate was $10.5 \%$ (199/1898).

According to stepwise multivariate analysis $(P R=0.005$ and $P E=0.001)$, several criteria were found to be independent variables predictive of mortality, including patient age $(\mathrm{OR}=1.1 ; 95 \% \mathrm{Cl}=1.0-1.1 ; \mathrm{p}<0.0001)$, the presence of small bowel perforation $(\mathrm{OR}=2.8 ; 95 \% \mathrm{Cl}=1.5-5.3 ; \mathrm{p}<0.0001)$, a delayed initial intervention (a delay exceeding 24 hours) $(\mathrm{OR}=1.8 ; 95 \% \mathrm{Cl}=1.5-3.7 ; \mathrm{p}<0.0001), \mathrm{ICU}$ admission $(\mathrm{OR}=5.9 ; 95 \% \mathrm{Cl}=3.6-9.5 ; \mathrm{p}<0.0001)$ and patient immunosuppression $(\mathrm{OR}=3.8 ; 95 \% \mathrm{Cl}=2.1-6.7 ; \mathrm{p}<0.0001)$.
}

\footnotetext{
* Correspondence: massimosartelli@gmail.com

${ }^{1}$ Department of Surgery, Macerata Hospital, Macerata, Italy

Full list of author information is available at the end of the article
} 


\section{Introduction}

Intra-abdominal infections (IAIs) include a wide spectrum of pathological conditions, ranging from uncomplicated appendicitis to faecal peritonitis [1].

In the event of complicated IAI the infection proceeds beyond a singularly affected organ and causes either localized peritonitis (intra-abdominal abscesses) or diffuse peritonitis. Effectively treating patients with complicated intra-abdominal infections involves both source control and antimicrobial therapy $[2,3]$.

In order to describe the epidemiological, clinical, microbiological, and surgical treatment profiles of complicated intra-abdominal infections (IAIs) in Europe, the World Society of Emergency Surgery (WSES) designed the CIAO Study (Complicated intra-abdominal infections observational study). The CIAO Study was conducted during 2012 across twenty European countries [4].

Given the interesting results of the CIAO Study, WSES designed a prospective observational study investigating the management of complicated intra-abdominal infections in a worldwide context.

The CIAOW study (Complicated intra-abdominal infections worldwide observational study) is a multicenter observational study underwent in 68 medical institutions worldwide during a six-month study period (October 2012-March 2013).

In January 2013 the preliminary results (2-month study period) of the CIAOW study were published [5].

WSES presents the definitive data of the CIAOW Study.

\section{Methods}

Aim

The purpose of the study was to describe the clinical, microbiological, and treatment profiles of both communityand healthcare-acquired complicated IAIs in a worldwide context.
Patients older than 18 years with both communityacquired and healthcare-associated IAIs were included in the database.

\section{Study population}

The CIAOW study is a multicenter observational study underwent in 68 medical institutions worldwide. The study included patients undergoing surgery or interventional drainage to address complicated IAIs.

Medical institutions from each continent participated in the study. The geographical distribution of the participating centers are represented in Figure 1.

\section{Study design}

The study did not attempt to change or modify the laboratory or clinical practices of the participating physicians, and neither informed consent nor formal approval by an Ethics Committee were required.

The study met the standards outlined in the Declaration of Helsinki and Good Epidemiological Practices.

The study was monitored by the coordination center, which investigated and verified missing or unclear data submitted to the central database. This study was performed under the direct supervision of the board of directors of WSES.

\section{Data collection}

In each centre, the coordinator collected and compiled data in an online case report system. These data included the following: (i) patient and disease characteristics, i.e., demographic data, type of infection (community- or healthcare-acquired), severity criteria, previous curative antibiotic therapy administered in the 7 days preceding surgery; (ii) origin of infection and surgical procedures performed; and (iii) microbiological data, i.e., identification of bacteria and microbial pathogens within the peritoneal

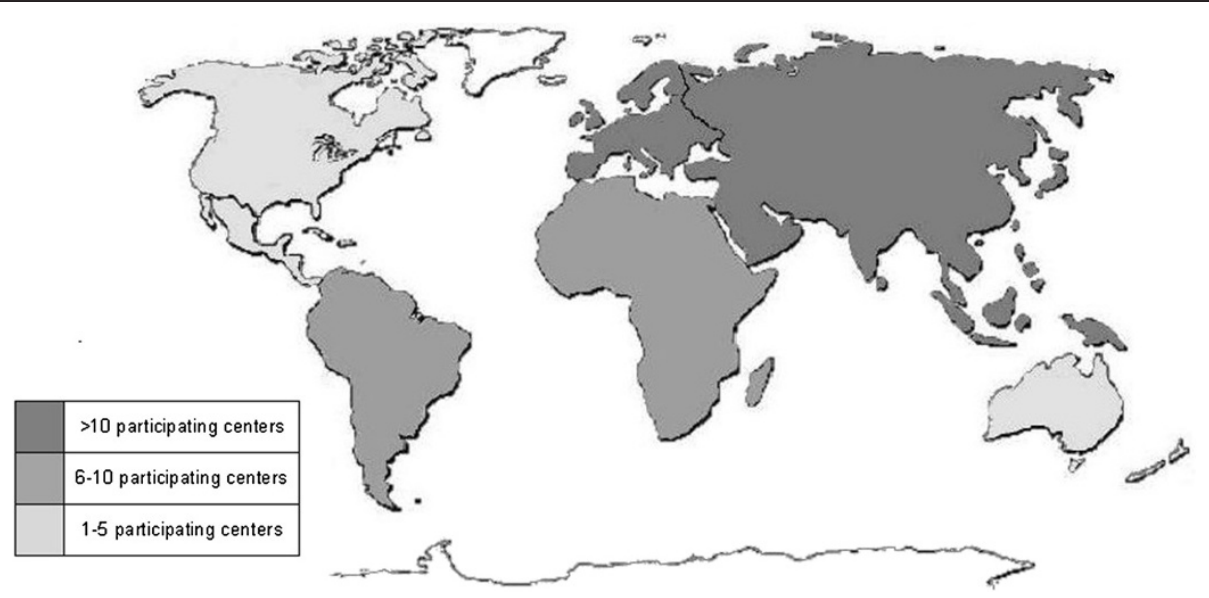

Figure 1 Participating centers for each continent. 
fluid, the presence of yeasts (if applicable), and the antibiotic susceptibilities of bacterial isolates.

The primary endpoints included the following:

- Clinical profiles of intra-abdominal infections

- Epidemiological profiles (epidemiology of the microorganisms isolated from intra-abdominal samples and these organisms' resistance to antibiotics)

- Management profiles

\section{Results}

\section{Patients}

2,020 cases were collected in the online case report system. 122 cases did not meet the inclusion criteria.

1,898 patients with a mean age of 51.6 years (range 18-99) were enrolled in the CIAOW study. 777 patients (41\%) were women and 1,121 (59\%) were men. Among these patients, 1,645 (86.7\%) were affected by communityacquired IAIs while the remaining 253 (13.3\%) suffered from heathcare-associated infections. Intraperitoneal specimens were collected from 1,190 (62.7\%) of the enrolled patients [213 patients (84.2\%) with Healthcare-associated infections and 977 (59.4\%) with Community-acquired infections].

827 patients $(43.6 \%)$ were affected by generalized peritonitis while 1071 (56.4\%) suffered from localized peritonitis or abscesses.

296 patients $(14.2 \%)$ were admitted in critical condition (severe sepsis/septic shock).

Table 1, 2 overview the clinical findings and radiological assessments recorded upon patient admission.

\section{Source control}

The various sources of infection are outlined in Table 3 . The most frequent source of infection was acute appendicitis; 633 cases (33.3\%) involved complicated appendicitis.

The open appendectomy was the most common means of addressing complicated appendicitis. 358 patients (56.5\%) admitted for complicated appendicitis underwent open appendectomies: 276 patients $(77.1 \%)$ for localized infection or abscesses and 82 patients (22.9\%) for generalized peritonitis. A laparoscopic appendectomy was performed for 226 patients (35.7\%) with complicated acute appendicitis; of these patients, $193(85.4 \%)$ underwent the procedure for localized peritonitis/abscesses and 33 (14.6\%) underwent the procedure for generalized peritonitis.

Open bowel resection was performed for 5 patients affected by complicated appendicitis. In the other 48 cases of complicated appendicitis (7.6\%), conservative treatment (percutaneous drainage, surgical drainage, and non-operative treatment) was performed. $3 \%$ of patients underwent percutaneous drainage (17/513) to address
Table 1 Clinical findings

\begin{tabular}{|c|c|}
\hline Clinical findings & $\begin{array}{c}\text { Patients } \\
\text { N } 1898(100 \%)\end{array}$ \\
\hline Abdominal pain & $288(15.1)$ \\
\hline Abdominal pain, abdominal rigidity & $284(15 \%)$ \\
\hline $\begin{array}{l}\text { Abdominal pain, abdominal rigidity, } \mathrm{T}>38^{\circ} \mathrm{C} \\
\text { or }<36^{\circ} \mathrm{C}, \mathrm{WBC}>12,000 \text { or }<4,000\end{array}$ & $314(16.5 \%)$ \\
\hline Abdominal pain, abdominal rigidity, $\mathrm{T}>38^{\circ} \mathrm{C}$ or $<36^{\circ} \mathrm{C}$, & $67(3.5)$ \\
\hline $\begin{array}{l}\text { Abdominal pain, abdominal rigidity, WBC }>12,000 \\
\text { or }<4,000\end{array}$ & $376(19.8 \%)$ \\
\hline Abdominal pain, $\mathrm{T}>38^{\circ} \mathrm{C}$ or $<36^{\circ} \mathrm{C}$, & $68(3.6 \%)$ \\
\hline $\begin{array}{l}\text { Abdominal pain, } \mathrm{T}>38^{\circ} \mathrm{C} \text { or }<36^{\circ} \mathrm{C}, \mathrm{WBC}>12,000 \\
\text { or }<4,000\end{array}$ & $139(7.3 \%)$ \\
\hline Abdominal pain, WBC $>12,000$ or $<4,000$ & $266(14 \%)$ \\
\hline $\mathrm{T}>38^{\circ} \mathrm{C}$ or $<36^{\circ} \mathrm{C}$ & $6(0.3 \%)$ \\
\hline $\mathrm{T}>38^{\circ} \mathrm{C}$ or $<36^{\circ} \mathrm{C}, \mathrm{WBC}>12,000$ or $<4,000$ & $12(0.6 \%)$ \\
\hline Abdominal rigidity, $\mathrm{WBC}>12,000$ or $<4,000$ & $9(0.5 \%)$ \\
\hline Abdominal rigidity & $2(0.1 \%)$ \\
\hline Abdominal rigidity, $\mathrm{T}>38^{\circ} \mathrm{C}$ or $<36^{\circ} \mathrm{C}$ & $1(0.05 \%)$ \\
\hline $\begin{array}{l}\text { Abdominal pain, abdominal rigidity, } \mathrm{T}>38^{\circ} \mathrm{C} \\
\text { or }<36^{\circ} \mathrm{C} \text {, WBC }>12,000 \text { or }<4,000\end{array}$ & $7(0.4 \%)$ \\
\hline WBC $>12,000$ or $<4,000$ & $11(0.6 \%)$ \\
\hline Not reported & $48(2.5 \%)$ \\
\hline
\end{tabular}

appendicular abscesses or localized intra-abdominal infections.

Among the patients with complicated cholecystitis (278), the open cholecystectomy was the most frequently performed procedure. $47.8 \%$ (133) and \% 36.7 (102) of cholecystitis patients underwent open and laparoscopic

Table 2 Radiological procedures

\begin{tabular}{lc}
\hline Radiological procedures & Patients \\
\hline Abdomen X ray & $\mathbf{1 8 9 8}(\mathbf{1 0 0 \% )}$ \\
Abdomen X ray, CT & $240(12.6 \%)$ \\
Abdomen X ray, ultrasound & $102(5.4 \%)$ \\
Abdomen X ray, ultrasound, CT & $356(18.7 \%)$ \\
Abdomen X ray, ultrasound, MRI & $112(5.9 \%)$ \\
Abdomen X ray, CT,ultrasound, MRI & $4(0.2 \%)$ \\
CT & $7(0.4 \%)$ \\
CT, MRI & $426(22.4 \%)$ \\
Ultrasound & $2(0.1 \%)$ \\
Ultrasound, CT & $384(20.2 \%)$ \\
Ultrasound, CT, MRI & $87(4.6 \%)$ \\
Ultrasound, MRI & $1(0.05 \%)$ \\
MRI & $3(0.1 \%)$ \\
Not reported & $1(0.05 \%)$ \\
\hline
\end{tabular}


Table 3 Source of infection

\begin{tabular}{lc}
\hline Source of infection & Patients \\
\hline Appendicitis & $\mathbf{1 8 9 8}(\mathbf{1 0 0 \% )}$ \\
Cholecystitis & $633(33.3 \%)$ \\
Post-operative & $278(14.6 \%)$ \\
Colonic non diverticular perforation & $170(15.9 \%)$ \\
Gastroduodenal perforations & $115(9.9 \%)$ \\
Diverticulitis & $253(13.3 \%)$ \\
Small bowel perforation & $106(5.6 \%)$ \\
Others & $145(7.6 \%)$ \\
PID & $122(6.4 \%)$ \\
Post traumatic perforation & $30(1.6 \%)$ \\
\hline
\end{tabular}

cholecystectomies, respectively. The remaining patients were treated with conservative methods (percutaneous drainage, non-operative treatment).

Among the patients with complicated diverticulitis (106) the Hartmann resection was the most frequently performed procedure. 48 patients (45.3\%) underwent a Hartmann resection. 31 of these patients (64.6\%) underwent a Hartmann resection for generalized peritonitis, while the remaining 17 (35.6\%) underwent the same procedure for localized peritonitis or abscesses. Colo-rectal resection was performed in 18 cases (17\%) (5 with and 13 without protective stoma).

The remaining patients received conservative treatment (percutaneous drainage, non-operative treatment, surgical drainage and stoma). 4 patients underwent laparoscopic drainage.

For patients with gastro-duodenal perforations (253 cases), the most common surgical procedure was gastroduodenal suture. 212 patients underwent open gastroduodenal suture $(83.8 \%)$ and 18 patients underwent laparoscopic gastro-duodenal suture (7.1\%). 12 patients (4.7\%) underwent gastro-duodenal resection and 6 patients $(2.4 \%)$ received conservative treatment. The remaining patients underwent alternative procedures.

Of the 145 patients with small bowel perforations, 98 underwent open small bowel resection (85.2\%) and 3 (2\%) underwent laparoscopic small bowel resection. 28 patients (19.3\%) were treated by stoma.

Among the 115 patients with colonic non-diverticular perforation, 42 (36.5\%) underwent Hartmann resection, $26(22.6 \%)$ underwent open resection with anastomosis and without stoma protection, and 26 underwent open resection with stoma protection (22.6\%).

170 cases $(8.9 \%)$ were attributable to post-operative infections.

Source control was successfully implemented for 1,735 patients (91.4\%).

\section{Microbiology}

Intraperitoneal specimens were collected from $1,190 \mathrm{pa}-$ tients $(62.7 \%)$.

These specimens were obtained from 977 of the 1,645 patients presenting with community-acquired intraabdominal infections (59.4\%).

Intraperitoneal specimens were collected from 213 $(84.2 \%)$ of the remaining 253 patients with nosocomial intra-abdominal infections.

The aerobic bacteria identified in intraoperative samples are reported In Table 4, 5 .

The microorganisms isolated in subsequent samples from peritoneal fluid are reported in Table 6 .

All the microorganisms isolated in both intraoperative and subsequent samples from peritoneal fluid are reported in Table 7.

The major pathogens involved in intra-abdominal infections were found to be Enterobacteriaceae.

Among the intra-operative isolates, Extended-Spectrum Beta-Lactamase (ESBL)-producing Escherichia coli isolates comprised 13.7\% (75/548) of all Escherichia coli isolates, while ESBL-positive Klebsiella pneumoniae isolates represented 18.6\% (26/140) of all Klebsiella pneumoniae isolates. ESBL-positive Enterobacteriaceae were more prevalent in patients with healthcare associated infections IAIs than they were in patients with community-acquired IAIs. ESBL-positive Escherichia coli isolates comprised

Table 4 Aerobic bacteria identified from intra-operative peritoneal fluid

\begin{tabular}{lc}
\hline Total & $\mathbf{1 . 3 3 0 ( 1 0 0 \% )}$ \\
\hline Aerobic Gram-negative bacteria & $\mathbf{9 5 7}(\mathbf{7 1 . 9 \% )}$ \\
Escherichia coli & $548(41.2 \%)$ \\
(Escherichia coli resistant to third generation & $75(5.6 \%)$ \\
cephalosporins) & \\
Klebsiella pneuumoniae & $140(10.5 \%)$ \\
(Klebsiella pneumoniae resistant to third & $26(1.4 \%)$ \\
generation cephalosporins) & \\
Klebsiella oxytoca & $11(0.8 \%)$ \\
(Klebsiella oxytoca resistant to third generation & $2(0.1)$ \\
cephalosporins) & \\
Enterobacter & $64(4.8 \%)$ \\
Proteus & $47(3.5 \%)$ \\
Pseudomonas & $74(5.6 \%)$ \\
Others & $73(5.6 \%)$ \\
Aerobic Gram-positive bacteria & $\mathbf{3 7 3}(\mathbf{2 9 . 1 \% )}$ \\
Enterococcus faecalis & $153(11.5 \%)$ \\
Enterococcus faecium & $58(4.4 \%)$ \\
Staphylococcus Aureus & $38(2.8 \%)$ \\
Streptococcus spp. & $85(6,4 \%)$ \\
Others & $39(2.9 \%)$ \\
\hline
\end{tabular}


Table 5 Aerobic bacteria from intra-operative samples in both community-acquired and healthcare-associated IAls

\begin{tabular}{|c|c|c|c|}
\hline Community-acquired IAIs & Isolates $\mathrm{n}^{\circ}$ & Healthcare-associated (nosocomial) IAIs & Isolates $n^{\circ}$ \\
\hline Aerobic bacteria & $1030(100 \%)$ & Aerobic bacteria & $300(100 \%)$ \\
\hline Escherichia coli & $456(44.3 \%)$ & Escherichia coli & $92(21 \%)$ \\
\hline $\begin{array}{l}\text { (Escherichia coli resistant to third generation } \\
\text { cephalosporins) }\end{array}$ & $56(5.4 \%)$ & $\begin{array}{l}\text { (Escherichia coli resistant to third generation } \\
\text { cephalosporins) }\end{array}$ & 19 (6.3\%) \\
\hline Klebsiella pneumoniae & $105(10.1 \%)$ & Klebsiella pneumoniae & $35(11.7 \%)$ \\
\hline $\begin{array}{l}\text { (Klebsiella pneumoniae resistant to third generation } \\
\text { cephalosporins) }\end{array}$ & $11(0.1 \%)$ & $\begin{array}{c}\text { (Klebsiella pneumoniae resistant to third generation } \\
\text { cephalosporins) }\end{array}$ & $15(5 \%)$ \\
\hline Pseudomonas & $56(5.4 \%)$ & Pseudomonas & $18(5.7 \%)$ \\
\hline Enterococcus faecalis & $106(10.3 \%)$ & Enterococcus faecalis & $47(15.7 \%)$ \\
\hline Enterococcus faecium & $38(3.7 \%)$ & Enterococcus faecium & $20(6.7 \%)$ \\
\hline
\end{tabular}

20.6\% (19/92) of all identified Escherichia coli isolates, while ESBL-positive Klebsiella pneumoniae isolates made up $42.8 \%(15 / 35)$ of all identified Klebsiella pneumoniae isolates.

Among all the microorganisms isolated in both intraoperative and subsequent samples from peritoneal fluid, there were 110 isolates of Escherichia coli ESBL, 39 isolates of Klebsiella pneumoniae ESBL, 2 isolates of Klebsiella Oxytoca ESBL. There were 5 isolates of Klebsiella pneumoniae resistant to Carbapenems.

Among the microorganisms isolated in the intraoperative samples, there were 74 isolates of Pseudomonas aeruginosa, comprising $5.6 \%$ of all aerobic identified bacteria isolates.

Table 6 Microorganisms identified from subsequent peritoneal samples

\begin{tabular}{lc}
\hline Total & $\mathbf{2 6 8}(\mathbf{1 0 0 \% )}$ \\
\hline Aerobic Gram-negative bacteria & $\mathbf{1 9 5}(\mathbf{7 2 . 7 \% )}$ \\
Escherichia coli & $105(41.8 \%)$ \\
(Escherichia coli resistant to third generation & $35(13 . \%)$ \\
cephalosporins) & \\
Klebsiella pneuumoniae & $41(15.3 \%)$ \\
(Klebsiella pneumoniae resistant to third & $13(4.8 \%)$ \\
generation cephalosporins) & \\
Pseudomonas & $20(7.4 \%)$ \\
Others & $29(10.8 \%)$ \\
Aerobic Gram-positive bacteria & $\mathbf{4 1}(\mathbf{1 5 . 3 \% )}$ \\
Enterococcus faecalis & $16(6 \%)$ \\
Enterococcus faecium & $10(3.4 \%)$ \\
Staphylococcus Aureus & $7(4 \%)$ \\
Others & $8(3 \%)$ \\
Bacteroides & $8(3 \%)$ \\
Candida albicans & $17(6 \%)$ \\
Non candida albicans & $6(2.2 \%)$ \\
Other yeats & $2(0.7 \%)$ \\
\hline
\end{tabular}

Table 7 Total of microorganisms identified from both intraoperative and subsequent peritoneal samples

Total 1826

Aerobic Gram-negative bacteria

$1826(100 \%)$

Escherichia coli

$1152(63 \%)$

(Escherichia coli resistant to third generation $653(35.7 \%)$ cephalosporins)

Klebsiella pneuumoniae

$110(6 \%)$

(Klebsiella pneumoniae resistant to third

$181(9.9 \%)$ generation cephalosporins)

$39(2.1 \%)$

Klebsiella oxytoca

$11(0.6 \%)$

(Klebsiella oxytoca resistant to third generation cephalosporins)

$75(4.1 \%)$

Enterobacter

$52(2.8 \%)$

Proteus

$94(5.1 \%)$

Pseudomonas

$102(5.6 \%)$

Others

$414(22.7 \%)$

Aerobic Gram-positive bacteria

$169(9.2 \%)$

Enterococcus faecalis

$68(3.7 \%)$

Enterococcus faecium

$46(2.5 \%)$

Staphylococcus Aureus

85 (4.6\%)

Streptococcus spp.

$47(2.6 \%)$

Others

$141(7.7 \%)$

$108(5.9 \%)$

Bacteroides

$3(0.2 \%)$

$11(0.6 \%)$

$22(1.2 \%)$

$117(6.4 \%)$

Candida spp.

$90(4.9 \%)$

$2(0.1 \%)$

(Candida albicans resistant to Fluconazole)

$27(1.4 \%)$

$3(0.1 \%)$

(non-albicans Candida resistant to Fluconazole)

$2(0.1 \%)$ 
Among all the microorganisms isolated in both intraoperative and subsequent samples from peritoneal fluid, there were 94 isolates of Pseudomonas aeruginosa, comprising $5.1 \%$ of all identified bacteria isolates.

The 2 Pseudomonas aeruginosa strains resistant to Carbapenems were also obtained from nosocomial infections.

Among all the aerobic gram-positive bacteria identified in the intraoperative samples, Enterococci (E. faecalis and E. faecium) were the most prevalent, representing $15.9 \%$ of all aerobic isolates, and were identified in 211 cases. Although Enterococci were also present in community-acquired infections, they were more prevalent in healthcare-associated infections (31.7\%: 67/211).

Among all the microorganisms isolated in both intraoperative and subsequent samples from peritoneal fluid Enterococci were 237/1826 (12.9\%).

11 glycopeptide-resistant Enterococci were identified; 5 were glycopeptide-resistant Enterococcus faecalis isolates and 6 were glycopeptide-resistant Enterococcus faecium isolates.

Tests for anaerobes were conducted for 486 patients.

Identified anaerobic bacteria from intra-operative specimens are reported in Table 8.

Among all the microorganisms isolated in both intraoperative and subsequent samples from peritoneal fluid, 141 anaerobes were observed. The most frequently identified anaerobic pathogen was Bacteroides. 108 Bacteroides isolates were observed during the course of the study.

In Table 9 are illustrated Candida spp. isolated in intraoperative specimens.

Among all the microorganisms isolated in both intraoperative and subsequent samples from peritoneal fluid, 117 Candida isolates were collectively identified (6\%). 90 were Candida albicans and 27 were non-albicans Candida.

\section{Outcome}

The overall mortality rate was $10.5 \%(199 / 1898)$.

565 patients $(29.8 \%)$ were admitted to the intensive care unit (ICU) in the early recovery phase immediately following surgery.

223 patients $(11.7 \%)$ ultimately required additional surgeries. $62(11.3 \%)$ of these patients underwent open abdominal procedures.

Table 8 Anaerobic bacteria identified from intra-operative peritoneal fluid

\begin{tabular}{lc}
\hline Anaerobes & $\mathbf{1 3 3}$ \\
\hline Bacteroides & $100(75 \%)$ \\
(Bacteroides resistant to Metronidazole) & $3(1.5 \%)$ \\
Clostridium & $11(8.2 \%)$ \\
Others & $22(16.5 \%)$ \\
\hline
\end{tabular}

Table 9 Candida isolates identified from intra-operative peritoneal fluid

\begin{tabular}{lc}
\hline Candida spp. & $\mathbf{9 4}$ \\
\hline Candida albicans & $73(78.7 \%)$ \\
(Candida albicans resistant to Fluconazole) & $2(2.1 \%)$ \\
Non-albicans Candida & $21(19.1 \%)$ \\
(non-albicans Candida resistant to Fluconazole) & $3(3.2 \%)$ \\
\hline
\end{tabular}

In the immediate post-operative clinical period $269 \mathrm{pa}$ tients were critically ill (132 with septic shock, 137 with severe sepsis).

According to univariate statistical analysis of the data (Table 10), septic shock $(\mathrm{OR}=14.9 ; 95 \% \mathrm{CI}=9.3-26.7 ; \mathrm{p}<$ $0.0001)$ and severe sepsis $(\mathrm{OR}=4.2 ; 95 \% \mathrm{CI}=2.8-6.3 ; \mathrm{p}<$ $0.0001)$ upon hospital admission were both predictive of patient mortality.

The setting of acquisition was also a variable found to be predictive of patient mortality (healthcare-associated infections: $\mathrm{OR}=3.1 ; 95 \% \mathrm{CI}=2.2-4.5 ; \mathrm{p}<0.0001)$.

Among the various sources of infection, colonic nondiverticular perforation $(\mathrm{OR}=21 ; 95 \% \mathrm{CI}=9.9-44.6 \mathrm{p}<$ $0.0001)$, complicated diverticulitis $(\mathrm{OR}=11 ; 95 \% \mathrm{CI}=$ 4.9-25.2; $\mathrm{p}<0.0001)$, small bowel perforation $(\mathrm{OR}=14.3$; $95 \% \mathrm{CI}=6.7-30.3 ; \mathrm{p}<0.0001)$ and post-operative infections $(\mathrm{OR}=19.1 ; 95 \% \mathrm{CI}=9.3-39.3 ; \mathrm{p}<0.0001)$ were significantly correlated with patient mortality.

\section{Table 10 Univariate analysis: risk factors for occurrence} of death during hospitalization

\begin{tabular}{|c|c|c|c|}
\hline Risk factors & Odds ratio & $95 \% \mathrm{Cl}$ & $\mathbf{p}$ \\
\hline \multicolumn{4}{|l|}{$\begin{array}{l}\text { Clinical condition upon hospital } \\
\text { admission }\end{array}$} \\
\hline Severe sepsis & 27.6 & $15.9-47.8$ & $<0.0001$ \\
\hline Septic shock & 14.6 & $8.7-24.4$ & $<0.0001$ \\
\hline Healthcare associated infection & 3.1 & $2.2-4.5$ & $<0.0001$ \\
\hline \multicolumn{4}{|l|}{ Source of infection } \\
\hline Colonic non-diverticular perforation & 21 & $9.9-44.6$ & $<0.0001$ \\
\hline Small bowel perforation & 125.7 & $29.1-542$ & $<0.0001$ \\
\hline Complicated diverticulitis & 11 & $4.9-25.2$ & $<0.0001$ \\
\hline Post-operative infections & 19.1 & $9.3-39.3$ & $<0.0001$ \\
\hline Delayed initial intervention & 2.6 & $1.8-3.5$ & $<0.0001$ \\
\hline \multicolumn{4}{|l|}{$\begin{array}{l}\text { Immediate post-operative } \\
\text { clinical course }\end{array}$} \\
\hline Severe sepsis & 33.8 & $19.5-58.4$ & $<0.0001$ \\
\hline Septic shock & 59.2 & 34.4-102.1 & $<0.0001$ \\
\hline ICU admission & 18.6 & $12-28.7$ & $<0.0001$ \\
\hline \multicolumn{4}{|l|}{ Comorbidities } \\
\hline Malignancy & 3.6 & $2.5-15.1$ & $p<0.0001$ \\
\hline Immunosoppression & 1.0 & $3.2-7.5$ & $p<0.0001$ \\
\hline Serious cardiovascular disease & 4.5 & $3.2-6.3$ & $p<0.0001$ \\
\hline
\end{tabular}


Mortality rates did not vary to a statistically significant degree between patients who received adequate source control and those who did not. However, a delayed initial intervention (a delay exceeding 24 hours) was associated with an increased mortality rate $(\mathrm{OR}=3.6 ; 95 \%$ $\mathrm{CI}=1.9-3.7 ; \mathrm{p}<0.0001)$.

The nature of the immediate post-operative clinical period was a significant predictor of mortality (severe sepsis: $\mathrm{OR}=10.5 ; 95 \% \mathrm{CI}=24.0-66.0 ; \mathrm{p}<0.0001$, septic shock: $\mathrm{OR}=39.8 ; 95 \% \mathrm{CI}=6.4-17.5 ; \mathrm{p}<0.0001)$. Patients requiring $\mathrm{ICU}$ admission $(\mathrm{OR}=12.9 ; 95 \% \mathrm{CI}=8.8-19.0$; $\mathrm{p}<0.0001)$ were also associated with increased mortality rates.

Also comorbidities were associated to patient mortality (Malignancy: $\mathrm{OR}=3.6 ; 95 \% \mathrm{CI}=2.5-15.1 ; \mathrm{p}<0.0001$, immunosuppression: $\mathrm{OR}=1.0 ; 95 \% \mathrm{CI}=3.2-7.5 ; \mathrm{p}<0.0001$, and serious cardiovascular disease: $\mathrm{OR}=4.5 ; 95 \% \mathrm{CI}=$ 3.2-6.3, $\mathrm{p}<0.0001$ ).

According to stepwise multivariate analysis $(\mathrm{PR}=0.005$ and $\mathrm{PE}=0.001$ ) (Table 11), several criteria were found to be independent variables predictive of mortality, including patient age $(\mathrm{OR}=1.1 ; 95 \% \mathrm{CI}=1.0-1.1 ; \mathrm{p}<0.0001)$, the presence of small bowel perforation: $\mathrm{OR}=2.8 ; 95 \%$ $\mathrm{CI}=1.5-5.3 ; \mathrm{p}<0.0001$ ), a delayed initial intervention (a delay exceeding 24 hours $)(\mathrm{OR}=1.8 ; 95 \% \mathrm{CI}=1.5-3.7 ; \mathrm{p}<$ 0.0001), ICU admission ( $\mathrm{OR}=5.9 ; 95 \% \mathrm{CI}=3.6-9.5 ; \mathrm{p}<$ $0.0001)$ and patient immunosuppression ( $\mathrm{OR}=3.8 ; 95 \%$ $\mathrm{CI}=2.1-6.7 ; \mathrm{p}<0.0001)$.

\section{Discussion}

The CIAOW Study confirmed that acute appendicitis is the most common intra-abdominal condition requiring emergency surgery worldwide. According to the WSES 2013 guidelines for management of intra-abdominal infections, both open and laparoscopic appendectomies are viable treatment options for complicated appendicitis [6]. CIAOW Study results indicate that the open approach was used in most patients and it was the most common approach in the patients with complicated appendicitis.

For patients with peri-appendiceal abscesses, the proper course of surgical treatment remains a point of

Table 11 Multivariate analysis: risk factors for occurrence of death during hospitalization

\begin{tabular}{lccc}
\hline Risk factors & Odds ratio & $\mathbf{9 5 \% C l}$ & $\mathbf{p}$ \\
\hline Age & 3.3 & $2.2-5$ & $<0.0001$ \\
Small bowel perforation & 27.6 & $15.9-47.8$ & $<0.0001$ \\
Delayed initial intervention & 14.6 & $8.7-24.4$ & $<0.0001$ \\
ICU admission & 2.3 & $1.5-3.7$ & $<0.0001$ \\
Immunosuppression & 3.8 & $2.1-6.7$ & $<0.0001$
\end{tabular}

Stepwise multivariate analysis, $\mathrm{PR}=0.005 \mathrm{E} \mathrm{PE}=0.001$ (Hosmer-Lemeshow chi2 $(8)=1.68$, area under ROC curve $=0.9465)$. contention in the medical community. Although guidelines for the management of intra-abdominal infections commonly assert that patients with peri-appendiceal abscesses should be treated with percutaneous imageguided drainage [5]. Percutaneous drainage with or without interval appendectomy to treat peri-appendiceal abscess results in fewer complications and shorter overall length of stay [6-8]. Data from CIAOW Study indicate that few patients underwent this procedure for a peri-appenceal abscess.

Laparoscopic cholecystectomy versus open cholecystectomy question for acute cholecystitis has been extensively investigated. Several studies showed that early laparoscopic cholecystectomy resulted in a significantly reduced length of stay, no major complications, and no significant difference in conversion rates when compared with initial antibiotic treatment and delayed laparoscopic cholecystectomy [9-12].

The open cholecystectomy was the most common means of treating complicated cholecystitis; $47.8 \%$ (133) of the patients with complicated cholecystitis underwent this procedure. By contrast, 36.7\% (102) underwent a laparoscopic procedure.

The optimal surgical management of colonic diverticular disease complicated by peritonitis remains a controversial issue. Hartmann's resection has been considered the procedure of choice in patients with generalized peritonitis and remains a safe technique for emergency colectomy in perforated diverticulitis, especially in elderly patients with multiple co-morbidities [13]. More recently, some reports have suggested that primary resection and anastomosis is the preferred approach to diverticulitis, even in the presence of diffuse peritonitis [14,15].

According to CIAOW Study data, the Hartmann resection was the most frequently performed procedure to address both complicated diverticulitis and non-diverticular colonic perforations worldwide.

The significance of microbiological analysis of infected peritoneal fluid in community-acquired intra-abdominal infections has been debated in recent years.

Although the absence of impact of bacteriological cultures has been documented especially in appendicitis [16], in this era of the broad spread of resistant microorganisms such as nosocomial and community extended-spectrum b-lactamase (ESBL) Enterobacteriaceae, carbapenemase producing gram negatives, b lactamand vancomycin resistant enterococci (VRE), the threat of resistance is a source of major concern for clinicians. Therefore the results of the microbiological analyses have great importance for the therapeutic strategy of every patients.

According to CIAOW Study data, intraperitoneal specimens were collected from $62.7 \%$ of patients with complicated intra-abdominal infections. 
Intraperitoneal specimens were collected in 59.4\% patients presenting with community-acquired intraabdominal infections.

Intraperitoneal specimens were collected from $84.2 \%$ of the patients with nosocomial intra-abdominal infections.

In many clinical laboratories, species identification and susceptibility testing of anaerobic isolates are not routinely performed. Tests for anaerobes were conducted for 486 patients.

The major pathogens involved in community-acquired intra-abdominal infections are Enterobacteriaceae, Streptococcus species, and certain anaerobes (particularly B. fragilis).

The main resistance threat in intra.-abdominal infections is posed by ESBL-producing Enterobacteriaceae, which are becoming increasingly common in communityacquired infections $[17,18]$.

According to CIAOW Study data, ESBL producers were the most commonly identified drug-resistant microorganism involved in IAIs.

Recent years have seen an escalating trend of Klebsiella pneumoniae Carbapenemase (KPC) production, which continues to cause serious multidrug-resistant infections around the world. The recent emergence of Carbapenem-resistant Enterobacteriaceae is a major threat to hospitalized patients [19].

5 identified isolates of Klebsiella pneumoniae proved resistant to Carbapenems.

Pseudomonas aeruginosa is one of the major nosocomial pathogens worldwide. It is intrinsically resistant to many drugs and is able to become resistant to virtually any antimicrobial agent.

The rate of Pseudomonas aeruginosa was $5.6 \%$ of all microorganisms isolated in the intra-operative samples. According to CIAOW study there was no significant difference between community and healthcare associate infections.

The 2 Pseudomonas aeruginosa strains resistant to Carbapenems were also obtained from nosocomial infections.

Enterococci are significant pathogens in intraabdominal infections. Among multidrug Gram positive bacteria, Enterococci remain a challenge. The evolution of antimicrobial resistance in these organisms poses enormous challenges for clinicians when faced with patients affected with Enterococcus infections. Enterococcus infections are difficult to treat because of both intrinsic and acquired resistance to many antibiotics.

Enterococci (E. faecalis and E. faecium) were the most common Gram positive aerobic isolates.

Although Enterococci were also identified in communityacquired infections, they were far more prevalent in nosocomial infections.

In the last years there has been a significant increase in the incidence of invasive infections due to Candida species.
Although the epidemiological role of Candida spp. in nosocomial peritonitis is not yet defined, the clinical role is significant, because Candida isolation is normally associated to a poor prognosis [20].

In the CIAOW Study 117 Candida isolates were collectively identified (6\%). 90 were Candida albicans and 27 were non-albicans Candida.

It is well known that patients with severe sepsis or septic shock may be complicated by high mortality rates. According to the CIAOW Study the overall mortality rate was $10.5 \%(199 / 1898)$.

$29.8 \%$ of patients were admitted to the ICU in the early recovery phase immediately following surgery. In the immediate post-operative clinical period 269 patients were critically ill (132 with septic shock, 137 with severe sepsis).

The surgical treatment strategies following an initial emergency laparotomy have been debated in the last years.

The decision whether and when to perform a relaparotomy in secondary peritonitis is largely subjective and based on professional experience. Factors indicative of progressive or persistent organ failure during early postoperative follow-up are the best indicators for ongoing infection and associated positive findings at relaparotomy [21-23].

Relaparotomy strategies may include either a relaparotomy, when the patient's condition demands it ("relaparotomy on-demand"), or a planned relaparotomy with temporarily abdomen closure or open abdomen [24-27].

In the CIAOW Study 223 post-operative patients (11.7\%) ultimately required additional surgeries. 62 (11.3\%) of these patients underwent open abdominal procedures.

According to univariate statistical analysis of the data, septic shock and severe sepsis upon hospital admission were both predictive of patient mortality.

The setting of acquisition was also a variable found to be predictive of patient mortality (healthcare-associated infections).

Among the various sources of infection, colonic nondiverticular perforation, complicated diverticulitis, small bowel perforation and post-operative infections were significantly correlated with patient mortality.

Mortality rates did not vary to a statistically significant degree between patients who received adequate source control and those who did not. However, a delayed initial intervention (a delay exceeding 24 hours) was associated with an increased mortality rate.

The nature of the immediate post-operative clinical period was a significant predictor of mortality. Patients requiring ICU admission were also associated with increased mortality rates.

Also comorbidities were associated to patient mortality.

According to stepwise multivariate analysis, several criteria were found to be independent variables predictive of 
mortality, including patient age, the presence of small bowel perforation, a delayed initial intervention (a delay exceeding 24 hours), ICU admission and patient immunosuppression.

\section{Conclusion}

Complicated intra-abdominal infections remain an important source of patient morbidity and are frequently associated with poor clinical prognoses, particularly for patients in high-risk categories.

Given the sweeping geographical distribution of the participating medical centers, the CIAOW Study gives an accurate description of the epidemiological, clinical, microbiological, and treatment profiles of complicated intra-abdominal infections worldwide.

\section{Competing interests}

The authors declare that they have no competing interests.

\section{Authors' contributions}

MS designed the study and wrote the manuscript. FCo and DC performed statistical analysis. All authors participated in the study.

\section{Author details}

${ }^{1}$ Department of Surgery, Macerata Hospital, Macerata, Italy. ${ }^{2}$ Emergency Surgery, Maggiore Parma Hospital, Parma, Italy. ${ }^{3}$ Department of General Surgery, Ospedali Riuniti, Bergamo, Italy. ${ }^{4}$ Department of Anestesiology, Ospedali Riuniti, Bergamo, Italy. ${ }^{5}$ Department of Surgery, Denver Health Medical Center, Denver, USA. ${ }^{6}$ American Board of Surgery, Philadelphia, USA. ${ }^{7}$ Division of Trauma, Emergency Surgery and Surgical Critical Care, Harvard Medical School, Massachusetts General Hospital, Massachusetts, USA. ${ }^{8}$ Department of Surgery, UC San Diego Health System, San Diego, USA. ${ }^{9}$ Department of Primary Care \& Emergency Medicine, Kyoto University Graduate School of Medicine, Kyoto, Japan. ${ }^{10}$ Department of Abdominal Surgery, University Hospital Meilahti, Helsinki, Finland. ${ }^{11}$ Department of Surgery, University of Newcastle, Newcastle, NSW, Australia. ${ }^{12}$ Department of Surgery, Govt Medical College and Hospital, Chandigarh, India. ${ }^{13}$ Department of General Surgery, Rambam Health Care Campus, Haifa, Israel. ${ }^{14}$ Department of Surgery, Adria Hospital Adria, Adria, Italy. ${ }^{15}$ Trauma Surgery Unit, Maggiore Hospital, Bologna, Italy. ${ }^{16}$ Department of Surgery, Maggiore Hospital, Bologna, Italy. ${ }^{17}$ Department of Surgery, Fundación Valle del Lilí, Cali, Colombia. ${ }^{18}$ Division of Trauma/Critical Care Department of Surgery Virginia Commonwealth University, Richmond, VA, USA. ${ }^{19}$ Division of Trauma Surgery, Campinas University, Campinas, Brazil. ${ }^{20}$ Department of Surgery, Monte Sinai Hospital, Juiz de Fora, Brazil. ${ }^{21}$ Department of Surgery, Emergency Unit, Ribeirão Preto, Brazil. ${ }^{22}$ Department of Surgery, Chang Gung Memorial Hospital, Taoyuan, Taiwan. ${ }^{23}$ Department of General Surgery, Hadassah Medical Center, Jerusalem, Israel. ${ }^{24}$ Department of Surgery, Tianjin Nankai Hospital, Nankai Clinical School of Medicine, Tianjin Medical University, Tianjin, China. ${ }^{25}$ Department of Surgery, Pt BDS Post-graduate Institute of Medical Sciences, Rohtak, India. ${ }^{26}$ Department of Surgery, MOSC Medical College, Cochin, India. ${ }^{27}$ Department of Surgery, SKIMS, Srinagar, India. ${ }^{28}$ Department of Surgery, Kovai Medical Center, Coimbatore, India. ${ }^{29}$ First Clinic of General Surgery, University Hospital/UMBAL/St George Plovdiv, Plovdiv, Bulgaria. ${ }^{30}$ Department of Surgery, Edendale Surgery, Pietermaritzburg, Republic of South Africa. ${ }^{31}$ Department of Surgery, Ahmadu Bello University Teaching Hospital Zaria, Kaduna, Nigeria. ${ }^{32}$ Department of Surgery, Mansoura University Hospital, Mansoura, Egypt. ${ }^{33}$ Department of Surgery, Faculdades Integradas Padre Albino, Catanduva, Brazil. ${ }^{34}$ Department of Surgery, Mazzoni Hospital, Ascoli Piceno, Italy. ${ }^{35}$ Department of Surgery, Mellini Hospital, Chiari, BS, Italy. ${ }^{36}$ Department of General and Digestive Surgery, Virgen de la Victoria, University Hospital, Malaga, Spain.

${ }^{37}$ Department of General Surgery and Surgical Oncology, Université de Nice Sophia-Antipolis, Universitary Hospital of Nice, Nice, France. ${ }^{38}$ Department of Surgery, Hospital and Oncological Centre, Novy Jicin, Czech Republic.

${ }^{39}$ Department of General Surgery, Lviv Emergency Hospital, Lviv, Ukraine.

${ }^{40}$ Department of Surgery, University Hospital Center Zagreb, Zagreb, Croatia.
${ }^{41}$ 3rd Department of General Surger Jagiellonian Univeristy, Narutowicz Hospital, Krakow, Poland. ${ }^{42}$ Department of Surgery, Mozyr City Hospital, Mozyr, Belarus. ${ }^{43}$ Department of Surgery, Ancona University, Ancona, Italy. ${ }^{44}$ Department of Surgery, Ripas Hospital, Bandar Seri Begawan, Brunei. ${ }^{45}$ Clinical Sciences, Regional Hospitals Limbe and Buea, Limbe, Cameroon. ${ }^{46}$ Department of Surgery, Severance Hospital, Yonsei University College of Medicine, Seoul, Republic of Korea. ${ }^{47}$ Division of Trauma and Surgical Critical Care, Department of Surgery, University of Ulsan, Seoul, Republic of Korea.

${ }^{48}$ II Cátedra de Clínica Quirúrgica, Hospital de Clínicas, Asuncion, Paraguay. ${ }^{49}$ Department of Surgery, Cutral Có Clinic, Cutral Có, Argentina.

${ }^{50}$ Department of Surgery, Faculty of Medicine Siriraj Hospital, Bangkok, Thailand. ${ }^{51}$ Department of Surgery, Thammasat University Hospital, Pathumthani, Thailand. ${ }^{52}$ Department of Surgery, Bahrain Defence Force Hospital, Manama, Bahrain. ${ }^{53}$ Department of Surgery, Hospital Regional de Alta Especialidad del Bajio, Leon, Mexico. ${ }^{54}$ Clinical and Experimental Sciences, Brescia Ospedali Civili, Brescia, Italy. ${ }^{55}$ General Surgery, Adana Numune Training and Research Hospital, Adana, Turkey. ${ }^{56}$ Visceral Surgery, Military Hospital Desgenettes, Lyon, France. ${ }^{57}$ Visceral Surgery, Teaching Hospital Yalgado Ouedraogo, Ouedraogo, Burkina Faso. ${ }^{58}$ Department of Acute and Critical care medicine, Tokyo Medical and Dental University, Tokyo, Japan. ${ }^{59}$ The Shock Trauma and Emergency Medical Center, Matsudo City Hospital, Chiba, Japan. ${ }^{60}$ Emergency and Critical Care Center of Nippon Medical School, Tama-Nagayama Hospital, Tokyo, Japan. ${ }^{61}$ Department of Surgery, Our Lady of Lourdes Hospital, Drogheda, Ireland. ${ }^{62}$ Department of Surgery, Port Shepstone Hospital, Port Shepstone, South Africa. ${ }^{63}$ Department of Surgery, Obafemi Awolowo UNiversity Hospital, Ile-Ife, Nigeria.

${ }^{64}$ Department of Emergency and Critical Care Medicine, Chiba University Hospital, Chiba, Japan. ${ }^{65}$ Depatment of Emergency Medicine, Kyoto Second Red Cross Hospital, Kyoto, Japan. ${ }^{66}$ Tajima emergency \& Critical Care Medical Center, Toyooka Public Hospital, Toyooka, Hyogo, Japan. ${ }^{67}$ Emergency and Critical Care Medicine, Jichi Medical University, Shimotsuke, Japan.

${ }^{68}$ Department of Surgery, Mayo General Hospital Castlebar Co. Mayo, Castlebar, Ireland.

Received: 2 April 2014 Accepted: 11 May 2014 Published: 14 May 2014

\section{References}

1. Menichetti F, Sganga G: Definition and classification of intra-abdominal infections. J Chemother 2009, 21(Suppl 1):3-4.

2. Marshall JC, Maier RV, Jimenez M, Dellinger EP: Source control in the management of severe sepsis and septic shock: an evidence-based review. Crit Care Med 2004, 32(11 Suppl):S513-S526.

3. Pieracci FM, Barie PS: Management of severe sepsis of abdominal origin. Scand J Surg 2007, 96(3):184-196.

4. Sartelli M, Catena F, Ansaloni L, Leppaniemi A, Taviloglu K, Goor H, Viale P, Lazzareschi DV, Coccolini F, Corbella D, Werra C, Marrelli D, Colizza S, Scibè R, Alis H, Torer N, Navarro S, Sakakushev B, Massalou D, Augustin G, Catani M, Kauhanen S, Pletinckx P, Kenig J, Saverio S, Jovine E, Guercioni G, Skrovina M, Diaz-Nieto R, Ferrero A, et al: Complicated intra-abdominal infections in Europe: a comprehensive review of the CIAO study. World J Emerg Surg 2012, 7(1):36.

5. Sartelli M, Catena F, Ansaloni L, Moore E, Malangoni M, Velmahos G, Coimbra R, Koike K, Leppaniemi A, Biffl W, Balogh Z, Bendinelli C, Gupta S, Kluger Y, Agresta F, Di Saverio S, Tugnoli G, Jovine E, Ordonez C, Gomes CA, Junior GA, Yuan KC, Bala M, Peev MP, Cui Y, Marwah S, Zachariah S, Sakakushev B, Kong V, Ahmed A, et al: Complicated intra-abdominal infections in a worldwide context: an observational prospective study (CIAOW Study). World J Emerg Surg 2013, 8(1):1.

6. Oliak D, Yamini D, Udani VM, Lewis RJ, Arnell T, Vargas H, Stamos MJ: Initial nonoperative management for periappendiceal abscess. Dis Colon Rectum 2001, 44:936-941.

7. Brown CV, Abrishami M, Muller M, Velmahos GC: Appendiceal abscess: immediate operation or percutaneous drainage? Am Surg 2003, 69:829-832.

8. Andersson RE, Petzold MG: Nonsurgical treatment of appendiceal abscess or phlegmon: a systematic review and meta-analysis. Ann Surg 2007, 246:741-748.

9. Lau H, Lo CY, Patil NG, Yuen WK: Early versus delayed-interval laparoscopic cholecystectomy for acute cholecystitis. A Meta Anal Surg Endosc 2006, 20(1):82-87. 
10. Papi C, Catarci M, D'Ambrosio L, Gili L, Koch M, Grassi GB, Capurso L: Timing of cholecystectomy for acute cholecystitis: a meta-analysis. Am J Gastroenterol 2004, 99(1):147-155.

11. Gurusamy KS, Samraj K: Early versus delayed laparoscopic cholecystectomy for acute cholecystitis. Cochrane Database Syst Rev 2006, 18(4):CD005440

12. Shikata S, Noguchi Y, Fukui T: Early versus delayed cholecystectomy for acute cholecystitis: a meta-analysis of randomized controlled trials. Surg Today 2005, 35(7):553-560.

13. McCafferty MH, Roth L, Jorden J: Current management of diverticulitis. Am Surg 2008, 74(11):1041-1049.

14. Salem L, Flum DR: Primary anastomosis or Hartmann's procedure for patients with diverticular peritonitis? A systematic review. Dis Colon Rectum 2004, 47(11):1953-1964.

15. Chandra V, Nelson H, Larson DR, Harrington JR: Impact of primary resection on the outcome of patients with perforated diverticulitis. Arch Surg 2004, 139(11):1221-1224.

16. Gladman MA, Knowles CH, Gladman LJ, Payne JG: Intra-operative culture in appendicitis: Traditional practice challenged. Ann R Coll Surg Engl 2004, 86(3):196-201.

17. Hawser SP, Bouchillon SK, Hoban DJ, Badal RE, Cantón R, Baquero F: Incidence and antimicrobial susceptibility of Escherichia coli and Klebsiella pneumoniae with extended-spectrum beta-lactamases in community- and hospital-associated intra-abdominal infections in Europe: results of the 2008 Study for Monitoring Antimicrobial Resistance Trends (SMART). Antimicrob Agents Chemother 2010, 54(7):3043-3046.

18. Ben-Ami R, Rodriguez-Bano J, Arsian H, Pitout JD, Quentin C, Calbo ES, Azap OK, Arpin C, Pascual A, Livermore DM, Garau J, Carmeli Y: A multinational survey of risk factors for infection with extended-spectrum $\beta$-lactamaseproducing Enterobacteriaceae in nonhospitalized patients. Clin Infect Dis 2009, 49:682-690

19. Lee GC, Burgess DS: Treatment of Klebsiella pneumoniae carbapenemase (KPC) infections: a review of published case series and case reports. Ann Clin Microbiol Antimicrob 2012, 11(13):32.

20. Montravers P, Dupont H, Gauzit R, Veber B, Auboyer C, Blin P, Hennequin C, Martin C: Candida as a risk factor for mortality in peritonitis. Crit Care Med 2006, 34(3):646-652.

21. van Ruler O, Lamme B, Gouma DJ, Reitsma JB, Boermeester MA: Variables associated with positive findings at relaparotomy in patients with secondary peritonitis. Crit Care Med 2007, 35(2):468-476.

22. Hutchins RR, Gunning MP, Lucas DN, Allen-Mersh TG, Soni NC: Relaparotomy for suspected intraperitoneal sepsis after abdominal surgery. World I Surg 2004, 28(2):137-141.

23. Lamme B, Mahler CW, van Ruler O, Gouma DJ, Reitsma JB, Boermeester MA: Clinical predictors of ongoing infection in secondary peritonitis: systematic review. World J Surg 2006, 30(12):2170-2181.

24. van Ruler O, Mahler CW, Boer KR, Reuland EA, Gooszen HG, Opmeer BC, de Graaf PW, Lamme B, Gerhards MF, Steller EP, van Till JW, de Borgie CJ, Gouma DJ, Reitsma JB, Boermeester MA: Dutch Peritonitis Study Group. Comparison of on-demand vs planned relaparotomy strategy in patients with severe peritonitis: a randomized trial. JAMA 2007, 298(8):865-872.

25. Amin Al, Shaikh IA: Topical negative pressure in managing severe peritonitis: a positive contribution? World I Gastroenterol 2009, 15(27):3394-3397.

26. Adkins AL, Robbins J, Villalba M, Bendick P, Shanley CJ: Open abdomen management of intra-abdominal sepsis. Am Surg 2004, 70:137-140.

27. Schein M: Planned reoperations and open management in critical intraabdominal infections: prospective experience in 52 cases. World J Surg 1991, 15:537-545.

doi:10.1186/1749-7922-9-37

Cite this article as: Sartelli et al:: Complicated intra-abdominal infections worldwide: the definitive data of the CIAOW Study. World Journal of Emergency Surgery 2014 9:37.

\section{Submit your next manuscript to BioMed Central and take full advantage of:}

- Convenient online submission

- Thorough peer review

- No space constraints or color figure charges

- Immediate publication on acceptance

- Inclusion in PubMed, CAS, Scopus and Google Scholar

- Research which is freely available for redistribution

Submit your manuscript at www.biomedcentral.com/submit
C Biomed Central 